\title{
Antioxidant activity of fish sauces including puffer (Lagocephalus wheeleri) fish sauce measured by the oxygen radical absorbance capacity method
}

\author{
KAZUKI HARADA ${ }^{1}$, TOSHIMICHI MAEDA ${ }^{1}$, YOSHIRO HASEGAWA ${ }^{1}$, \\ TAKUSHI TOKUNAGA ${ }^{1}$, YOSHIYUKI TAMURA ${ }^{2}$ and TAKEO KOIZUMI ${ }^{3}$
}

\begin{abstract}
${ }^{1}$ Course of Resource Management and Food Science, Graduate School of Fisheries Science, National Fisheries University, Independent Administrative Institution, The Ministry of Agriculture Forestry and Fisheries of Japan, Yamaguchi 759-6595;

${ }^{2}$ Department of Career Design, Faculty of Industrial Sociology, Hagoromo University of International Studies, Osaka 592-8344; ${ }^{3}$ Department of Brewing and Fermentation, Faculty of Applied Bio-Science,

Tokyo University of Agriculture, Tokyo 156-8502, Japan
\end{abstract}

Received February 9, 2010; Accepted April 23, 2010

DOI: $10.3892 / \mathrm{mmr} 00000313$

\begin{abstract}
Fish sauces are fermented seasonings traditionally used throughout Asia, including Japan. Here, we report on the antioxidant activity of 30 fish sauces, among them a puffer fish sauce developed specifically for this study. To determine the antioxidant activity (i.e., the peroxyl radical elimination capacity) of the fish sauces, the oxygen radical absorbance capacity (ORAC) was measured. ORAC values ranged between $10^{4} \mu \mathrm{mol}$ (flatfish sauce 1) and $10^{3} \mu \mathrm{mol}$ (sandfish sauce) trolox equivalent (TE)/100 $\mathrm{ml}$ of fish sauce. Hydroxyl radical scavenging activity $\left(\mathrm{IC}_{50}\right)$ was measured using electron spin resonance. $\mathrm{IC}_{50}$ values ranged between $0.081 \%$ (puffer fish sauce) and $0.653 \%$ (sardine fish sauce 7). Puffer fish sauce had a high ORAC value $(8,365 \mu \mathrm{mol}$ TE/100 ml) and the highest hydroxyl radical scavenging activity (0.081). The relationship between the ORAC and $\mathrm{IC}_{50}$ values of the 30 fish sauces was determined to be intermediate $(r=-0.521$, $\mathrm{p}=0.01)$.
\end{abstract}

\section{Introduction}

Active oxygen species generated in the body cause damage to DNA and the lipid membrane structure of cells, and have been implicated in the processes of aging and cancer development (1). It is therefore important to eliminate excess active oxygen within the body. Antioxidants absorbed from food have been

Correspondence to: Dr Kazuki Harada, Course of Resource Management and Food Science, Graduate School of Fisheries Science, National Fisheries University, Independent Administrative Institution, The Ministry of Agriculture Forestry and Fisheries of Japan, 2-7-1 Nagata-Honmachi, Shimonoseki-shi, Yamaguchi 759-6595, Japan E-mail: kazuki@fish-u.ac.jp

Key words: antioxidant activity, fish sauce, oxygen radical absorbance capacity, electron spin resonance shown to be effective scavengers of active oxygen (2). Our research group has previously reported on the peroxyl and hydroxyl radical scavenging activities of fish sauce $(3,4)$, sea urchin gonads (5), gelatin gel food 'Nikogori' made from fish meat (6-9), dried bonito stock (Katsuo-dashi) (10), buckwheat $(11,12)$ and soy sauces $(13,14)$ measured by chemiluminescence and electron spin resonance (ESR) spectroscopy. We have also demonstrated the DNA protective activities of fish sauces, including tiger puffer (Takifugu rubripes) fish sauce, against hydroxyl radicals using an apurinic/apyrimidinic (AP) site assay (15).

Fish sauces are traditional seasonings used in Asian, including Japanese, cuisine, and have been studied in various countries, including countries outside of Asia (16-18). The measurement of oxygen radical absorbance capacity (ORAC) using fluorescence intensity for the determination of antioxidant activity (in the form of peroxyl radical elimination capacity) has been approved by the USDA (United States Department of Agriculture). Since Cao et al first developed the method in 1993 (19), various studies have applied the ORAC assay in both the US (20-26) and Japan (27-31). Though Yamada et al reported the ORAC value of dried bonito stock (Katsuo-dashi) (32,33), no studies have determined the ORAC value of fish sauce.

Here, we report on the antioxidant activity (the peroxyl radical elimination capacity) of 30 fish sauces, among them a puffer fish sauce developed specifically for this study, by comparing the ORAC values of the sauces to their hydroxyl radical scavenging activities as measured by ESR spectrometry. The puffer fish sauce was compared to previously experimentally developed and commercially available fish sauces.

\section{Materials and methods}

Fish sauce samples. The fish sauces used in the study are listed in Table I. The antioxidant activity of the unnumbered fish sauces was reported in our previous study (4). The puffer 
Table I. List of the examined fish sauces.

\begin{tabular}{|c|c|c|c|c|}
\hline No. & Type of sauce & Original name & Ingredients besides salt & Country of production \\
\hline 1 & Squid fish sauce 4 & Ishiri 3 & Squid & Japan \\
\hline 2 & Squid fish sauce 5 & & Squid, soybean, wheat and koji mold & Japan \\
\hline 3 & Squid fish sauce 6 & Ishiri 4 & Squid & Japan \\
\hline 4 & Sardine fish sauce 6 & & Sardine, soybean and barley & Japan \\
\hline 5 & Sardine fish sauce 7 & Shottsuru 3 & Sardine and seaweed & Japan \\
\hline 6 & Sardine fish sauce 8 & Ishiru 2 & Sardine and sugar & Japan \\
\hline 7 & Anchovy fish sauce 1 & Nam plaa 3 & Anchovy and sugar & Thailand \\
\hline 8 & Anchovy fish sauce 2 & & Anchovy & Japan \\
\hline 9 & $\begin{array}{l}\text { Anchovy fish sauce } 3^{4} \\
\text { (formerly fish sauce } 4 \text { ) }\end{array}$ & Nam plaa 2 & Anchovy and sugar & Thailand \\
\hline 10 & Anchovy fish sauce 4 & Nam plaa 4 & Anchovy and sugar & P.R. China \\
\hline 11 & Anchovy fish sauce 5 & & Anchovy, soybean, wheat and koji mold & Japan \\
\hline 12 & Anchovy fish sauce 6 & & Anchovy, soybean, wheat and koji mold & Japan \\
\hline 13 & Salmon fish sauce 4 & & Salmon, soybean, wheat and koji mold & Japan \\
\hline 14 & Sea-bream fish sauce 1 & & Sea-bream and rice & Japan \\
\hline 15 & Sea-bream fish sauce 2 & & Sea-bream and chicken egg white & Japan \\
\hline 16 & Flatfish fish sauce 1 & & Flatfish, soybean, wheat and koji mold & Japan \\
\hline 17 & Flatfish fish sauce 2 & & $\begin{array}{l}\text { Internal organs of flatfish, soybean, } \\
\text { wheat and koji mold }\end{array}$ & Japan \\
\hline 18 & Puffer fish sauce & & Puffer, soybean, wheat and koji mold & Japan \\
\hline 19 & Ayu fish sauce & & Ayu & Japan \\
\hline 20 & Cod fish sauce & & Cod, soybean, wheat and koji mold & Japan \\
\hline 21 & Sandfish fish sauce ${ }^{4}$ & Shottsuru 1 & Sandfish & Japan \\
\hline 22 & Sand lance fish sauce ${ }^{4}$ & Ikanago shoyu & Sand lance & Japan \\
\hline 23 & North Pacific lightfish fish sauce & & North Pacific lightfish and rice & Japan \\
\hline 24 & Fish sauce $2^{4}$ & Yuiru & Fish & P.R. China \\
\hline 25 & Fish sauce 4 & Nam plaa 5 & Fish & Thailand \\
\hline 26 & Fish sauce 5 & & Fish and alcohol & Japan \\
\hline 27 & Oyster sauce 2 & & Oyster, sugar and amino acid & Japan \\
\hline 28 & Shrimp sauce 2 & & Shrimp, amino acid and alcohol & Japan \\
\hline 29 & Sea urchin gonad fish sauce & & Sea urchin gonad, sugar and onion & Japan \\
\hline 30 & Walleye pollack roe fish sauce & & Walleye pollack roe, amino acid and alcohol & Japan \\
\hline
\end{tabular}

fish sauce was developed at our laboratory using the flesh, skin and bones (but not the internal organs, which contain the poison tetrodotoxin) from the white chestnut puffer fish (Lagocephalus wheeleri Abe, Tabeta et Kitahama). The puffer fish materials were combined with soybean, wheat, soy sauce koji mold (Aspergillus sojae), $\mathrm{NaCl}$ and water, then fermented for approximately 1 year at room temperature. For the experiments, the supernatant from the original fermented mash was used after sterilization (15).

Chemicals. 2,2'-Azobis (2-amidinopropane) dihydrochloride (AAPH) and dipotassium hydrogenphosphate $\left(\mathrm{K}_{2} \mathrm{HPO}_{4}\right)$ were obtained from Wako Pure Chemical, Ltd. (Osaka, Japan). Potassium dihydrogenphosphate $\left(\mathrm{KH}_{2} \mathrm{PO}_{4}\right)$ was obtained from Kanto Chemical Co., Inc. (Tokyo, Japan) and hydrogen peroxide $\left(\mathrm{H}_{2} \mathrm{O}_{2}\right)$ from Santoku Chemical Co., Ltd. (Tokyo, Japan). Fluorescein sodium salt and iron (II) sulfate heptahydrate $\left(\mathrm{FeSO}_{4} \cdot 7 \mathrm{H}_{2} \mathrm{O}\right)$ were obtained from Sigma-Aldrich Japan (Tokyo, Japan). A spin trapping reagent, 5,5-dimethyl-1-pyrroline
$\mathrm{N}$-oxide (DMPO), as well as 6-hydroxy-2,5,7,8-tetramethylchroman-2-carboxylic acid (trolox) were purchased from Tokyo Kasei Kogyo Co., Ltd. (Tokyo, Japan).

Sample preparation. Phosphate buffer was used as the assay (control) buffer and was prepared by combining $75 \mathrm{mM}$ $\mathrm{K}_{2} \mathrm{HPO}_{4}$ and $75 \mathrm{mM} \mathrm{KH} \mathrm{PO}_{4}$ for a final volume of $75 \mu \mathrm{mol}$, adjusted to $\mathrm{pH}$ 7.0. AAPH reagent was dissolved in the buffer at a concentration of $31.7 \mathrm{mM}$. Fluorescein working solution was prepared at a concentration of $94.4 \mathrm{nM}$ by dissolving fluorescein sodium salt in the buffer. Trolox standard solutions were prepared at concentrations of 100, 50, 25, 12.5 and $6.25 \mu \mathrm{M}$ by dissolving trolox in the buffer.

Measurement of oxygen radical absorbance capacity. The ORAC value was obtained by measuring the peroxyl radical elimination capacity of peroxyl radicals generated by AAPH reagent, and by measuring the time lapse degradation of fluorescein (i.e., the rate of decrease in the intensity of 
fluorescence) (21). The ORAC assay was performed on a 96-well multilabel microplate reader (Mithras LB940; Berthold Technologies $\mathrm{GmbH} \& \mathrm{Co}$. KG) as described by Huang et al $(22,23,25)$. In brief, $20 \mu \mathrm{l}$ each of sample buffer (obtained by appropriate dilution with assay buffer), various concentrations of trolox standard solution (for construction of a standard curve) or blank buffer (as a control) were placed in the individual wells of a 96-well transparent microplate (Sanplatec Corp., Osaka, Japan). Fluorescein working solution $(200 \mu \mathrm{l})$ was added and the wells were agitated at $37^{\circ} \mathrm{C}$ for $10 \mathrm{~min}$. Subsequently, $75 \mu \mathrm{l}$ of AAPH solution was added to each of the wells to initiate the reaction. The total volume of each reaction solution was $295 \mu 1$. The fluorescence intensity [485 nm (excitation)/535 nm (emission)] was then measured every 2 min over $90 \mathrm{~min}$ at $\mathrm{pH} 7.4$ and $37^{\circ} \mathrm{C}$. As the reaction progressed, fluorescein was consumed and the fluorescence intensity decreased. The inhibition of fluorescence decay was taken to indicate the presence of an antioxidant.

Typical ORAC assay kinetic curves in the presence of various concentrations of trolox are shown in Fig. 1. ORAC values were determined:

The area under the kinetic curve (AUC) of the standards and samples was calculated as follows:

AUC $=\left(0.5+\mathrm{f}_{10 \text { min }} / \mathrm{f}_{8 \text { min }}+\mathrm{f}_{12 \text { min }} / \mathrm{f}_{8 \text { min }}+\mathrm{f}_{14 \text { min }} / \mathrm{f}_{8 \text { min }}+\mathrm{f}_{90 \text { min }} /\right.$ $\left.\mathrm{f}_{8 \text { min }}\right) \times 2$

where $\mathrm{f}_{\mathrm{x} \min }=$ fluorescence reading at cycle $\mathrm{x} \min (23)$.

The standard regression line was obtained by plotting the trolox concentrations against the net $\mathrm{AUC}_{\text {trolox }}$ of each concentration:

Net $\mathrm{AUC}_{\text {trolox }}=\mathrm{AUC}_{\text {trolox }}-\mathrm{AUC}_{\text {control }}$

Net $\mathrm{AUC}_{\text {sample }}=\mathrm{AUC}_{\text {sample }}-\mathrm{AUC}_{\text {control }}$

where $\mathrm{AUC}_{\text {trolox }}=\mathrm{AUC}$ in the presence of trolox; $\mathrm{AUC}_{\text {control }}=$ AUC with blank control; $\mathrm{AUC}_{\text {sample }}$, AUC with sample buffer. The horizontal axis was the net $\mathrm{AUC}_{\text {trolox }}$; the vertical axis, the concentration of trolox.

The equation $\mathrm{Y}=\mathrm{ax}+\mathrm{b}$ was derived from the above data, and the values for $\mathrm{a}$ and $\mathrm{b}$ were obtained.

The final ORAC values of the samples were calculated using the equation:

ORAC value $(\mu \mathrm{mol}$ trolox equivalent $/ 100 \mathrm{ml})=[\mathrm{a} \mathrm{x}$ (net $\left.\left.\mathrm{AUC}_{\text {sample }}\right)\right] \times 100 /[$ sample]

where $[$ sample $]=$ the diluted concentration ratio of the sample.

Data were analyzed using Microsoft Excel.

Electron spin resonance analysis. ESR was conducted as previously described $(5,10-12,14,15)$. Briefly, hydroxyl radical generation was first examined by the DMPO method and iron (II) sulfate with or without the fish sauce samples. Next, the addition of $8.8 \mathrm{mM} \mathrm{H}_{2} \mathrm{O}_{2}(50 \mu \mathrm{l})$ to the reaction mixture $(320 \mu \mathrm{l})$ was used to initiate Fenton's reaction as depicted in the chemical equation: $\mathrm{Fe}^{2+}+\mathrm{H}_{2} \mathrm{O}_{2} \rightarrow \mathrm{Fe}^{3+}+\cdot \mathrm{OH}+\mathrm{OH}^{-}$. After 1 min of hydroxyl radical generation, spin adduct DMPO-OH. was measured using the ESR spectrometer (JES-FR30; JEOL

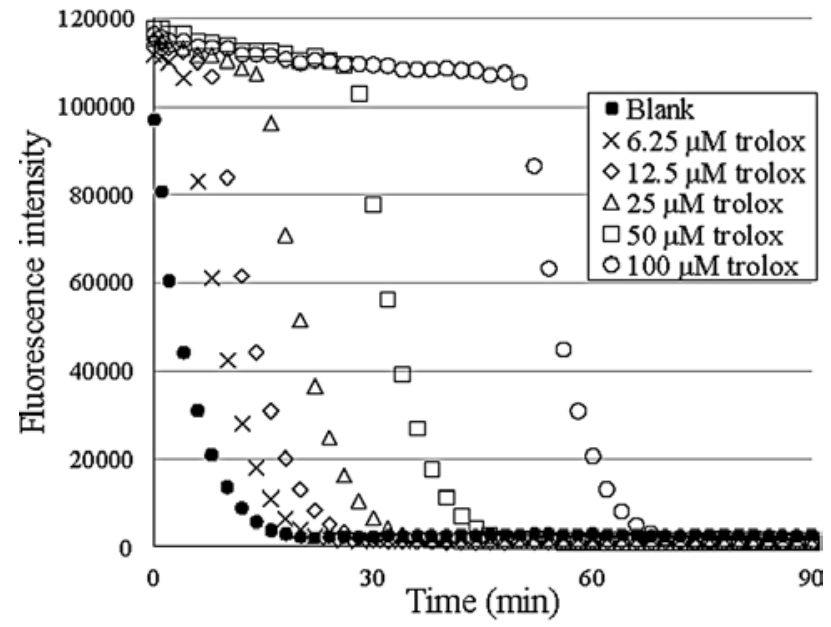

Figure 1. Typical fluorescence decay curves induced by AAPH in the presence of different concentrations of trolox.

Ltd., Tokyo, Japan). ESR measurement conditions were: output, $4 \mathrm{~mW}$ (9.4 GHz); magnetic field, 342.790 $\pm 5 \mathrm{mT}$; modulation amplitude, $0.079 \mathrm{mT}$; time constant, $0.1 \mathrm{sec}$; sweeping time, $1 \mathrm{~min}$; amplification ratio, 32-125.

Calculation of the $\mathrm{IC}_{50}$ of hydroxyl radical scavenging. $\mathrm{IC}_{50}$ values were defined as the concentration of each fish sauce that reduced the control peak height ratio of ESR (generation of hydroxyl radical) by half. The antioxidative value was calculated using the formula: $(\log$ Io/I) x 100, where Io $=$ ESR peak height ratio as the control, and $\mathrm{I}=\mathrm{ESR}$ peak height ratio as the samples. Thus, the $\mathrm{IC}_{50}$ value was the concentration of samples at $\mathrm{Io} / \mathrm{I}=1 / 2$, calculated from the antioxidant results of ESR obtained in the experiments $(5,10-12,14,15)$.

\section{Results}

Oxygen radical absorbance capacity values. As shown in Fig. 2, ORAC values ranged between 9,664 and 1,001 $\mu \mathrm{mol}$ trolox equivalent (TE)/100 $\mathrm{ml}$ of flatfish sauce 1 or sandfish sauce, respectively. The flatfish, squid, puffer, ayu, salmon and cod fish sauces had high ORAC values $(>6,000 \mu \mathrm{mol}$ TE/100 $\mathrm{ml})$. The ORAC value of puffer fish sauce was the fourth highest value at $8,365 \mu \mathrm{mol} \mathrm{TE} / 100 \mathrm{ml}$. Sauces containing soybean, wheat and koji mold tended to have higher ORAC values, while the sardine, anchovy, sandfish and sea-bream fish sauces had lower ORAC values (i.e., weak antioxidant activity) ranging between 1,000 and 5,500 $\mu \mathrm{mol} \mathrm{TE} / 100 \mathrm{ml}$. Sardine fish sauce 7, 8 and sandfish sauce had the lowest ORAC values, of $<2,000$. A similar trend was reported in a previous study (4), in which squid fish sauces had high antioxidant activity and sardine fish sauces had weak antioxidant activity, determined using chemiluminescence. The concurrence of these results is not unexpected, since both studies measured peroxyl radical elimination capacity or scavenging activity. The average ORAC value of the 30 types of fish sauce was 5,060 $\mu \mathrm{mol} \mathrm{TE} / 100 \mathrm{ml}$. The ORAC value of soy sauce (light color soy sauce) was 4,944 $\mu \mathrm{mol} \mathrm{TE} / 100 \mathrm{ml}$. This value was similar to the average ORAC value of the fish sauces (unpublished data). 


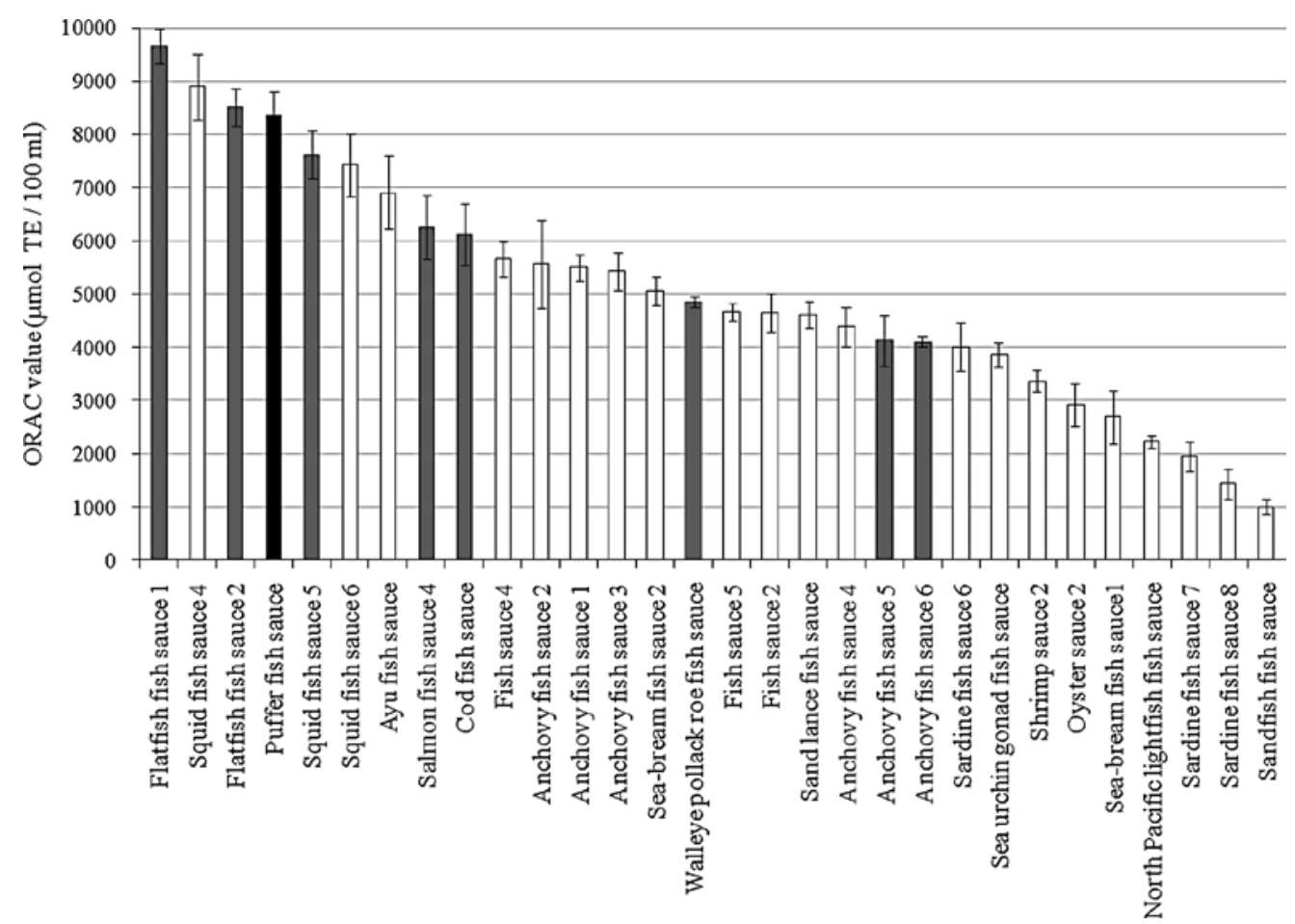

Figure 2. ORAC values ( $\mu$ mol trolox equivalent/100 ml) representing the peroxyl radical elimination capacity of the 30 types of fish sauce. The black bar represents the puffer fish sauce, and the gray bars represent the fish sauces that include soybean, wheat and koji mold $(\mathrm{n}=3)$.

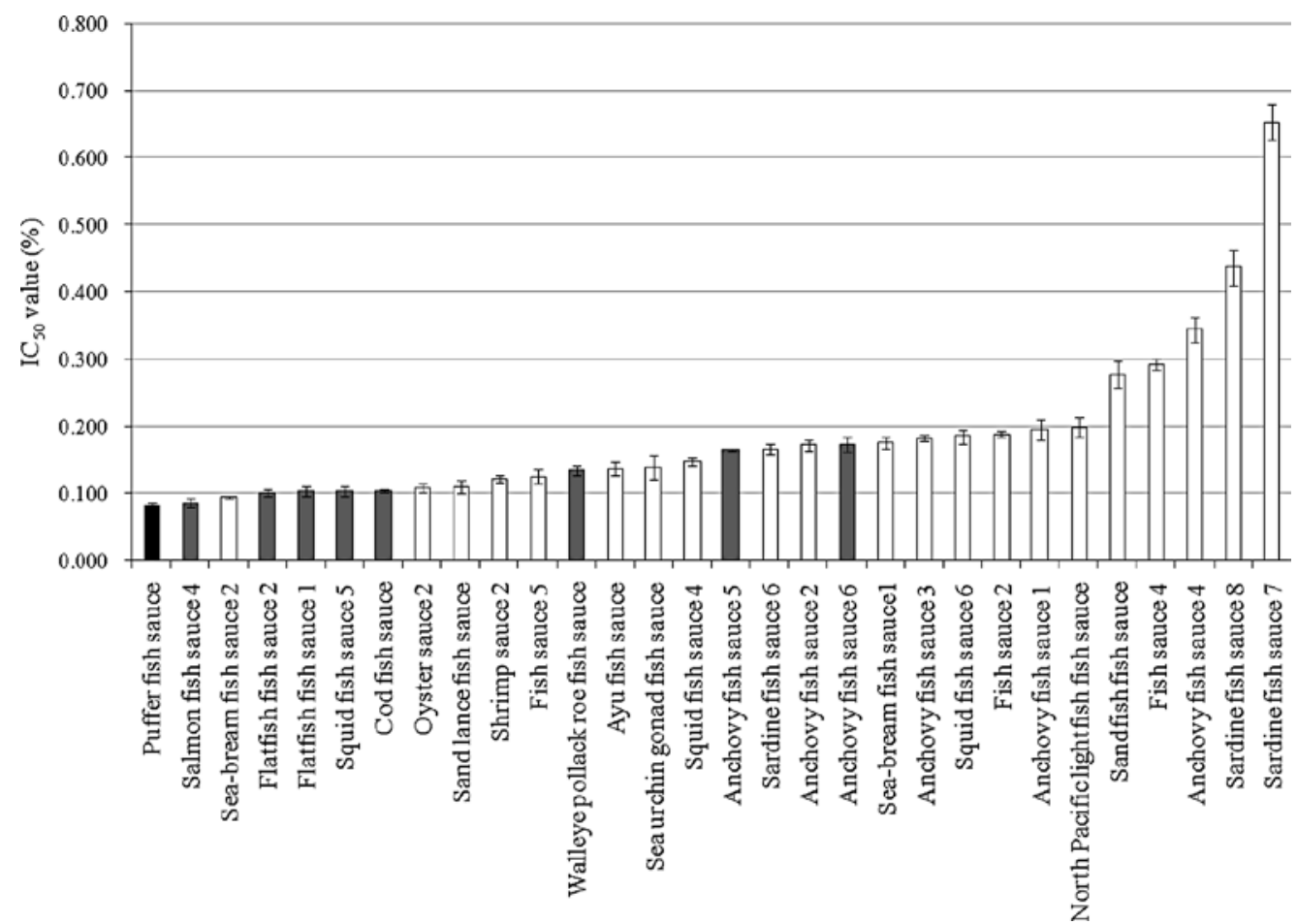

Figure 3. $\mathrm{IC}_{50}$ values (\%) representing the hydroxyl radical scavenging activities of the 30 types of fish sauce. The black bar represents the puffer fish sauce, and the gray bars represent the fish sauces that include soybean, wheat and koji mold $(\mathrm{n}=3)$.

$I C_{50}$ values from electron spin resonance spectrometry. The $\mathrm{IC}_{50}$ value was estimated from the results of ESR as the hydroxyl radical scavenging activity. The order of strength of hydroxyl radical scavenging activity is shown in Fig. 3; the lower the height of the bar, the stronger the radical scavenging activity. Based on the data, the $\mathrm{IC}_{50}$ values (\%) ranged between 0.081 (puffer fish sauce) and 0.653 (sardine fish sauce 7). The puffer fish sauce made using white chestnut puffer showed the highest hydroxyl radical scavenging activity, though previously we reported the $\mathrm{IC}_{50}$ of puffer fish sauce made with tiger 
puffer (Takifugu rubripes Temminck et Schlegel) to be $0.20 \%$ (15). The flatfish, puffer, salmon and cod fish sauces had high hydroxyl radical scavenging activities, with $\mathrm{IC}_{50}$ values $<0.105 \%$. Fish sauces with soybean, wheat and koji mold as ingredients tended to have higher hydroxyl radical scavenging activities. By contrat, the $\mathrm{IC}_{50}$ values of the squid fish sauces ranged between 0.104 and $0.185 \%$, though they had high antioxidant activities based on the ORAC values. Sardine and sandfish sauces had weak hydroxyl radical scavenging activities as well as low ORAC values.

Relationship between ORAC and $I_{50}$ values. ORAC values represented peroxyl radical elimination capacity and $\mathrm{IC}_{50}$ values represented hydroxyl radical scavenging activities. The relationship between the two was analyzed using the correlation coefficient (r), line regression and coefficient of determination $\left(\mathrm{R}^{2}\right)$ (Fig. 4). The regression line equation was $y=-9712.3 x+6836.4$, the correlation coefficient was -0.521 and the coefficient of determination was 0.272 . Therefore, the correlation was found to be intermediate at $\mathrm{p}=0.01$.

\section{Discussion}

We previously demonstrated, using chemiluminescence, ESR and an apurinic/apyrimidinic site assay, that fish sauces commonly used for seasoning foods in Asia have high antioxidant activities, $(3,4,15)$. The data from these previous studies and the current study reveal that the sauces with the weakest antioxidant activity are fish sauce 1, determined using chemiluminescence $(0.246 \%)$ (4), sandfish sauce, determined by measuring ORAC $(1,001 \mu \mathrm{mol} \mathrm{TE} / 100 \mathrm{ml})$, and sardine fish sauce 7 , determined using ESR $(0.653 \%)$. When sardine fish sauce 7 was diluted 153 -fold, the $\mathrm{IC}_{50}$ value was $0.653 \%$, half $(50 \%)$ of the scavenging activity of the generated hydroxyl radicals. According to the USDA databases (34), the ORAC value of sandfish sauce $(1,001 \mu \mathrm{mol} \mathrm{TE} / 100 \mathrm{ml})$ was higher than the values of apple juice (408 $\mu \mathrm{mol} \mathrm{TE} / 100 \mathrm{ml})$, pear juice (704), orange juice (726), white grape juice (793), lime juice (823), canned tomato juice (486), canned vegetable juice (548), apple vinegar (270) and red wine vinegar (410). Therefore, even fish sauces with weak antioxidative activity had higher antioxidant activity than fruit and vegetative juices.

Puffer fish sauce had a high ORAC value $(8,365 \mu \mathrm{mol}$ $\mathrm{TE} / 100 \mathrm{ml})$ and the lowest $\mathrm{IC}_{50}$ value $(0.081 \%)$ - in other words, the highest hydroxyl radical scavenging activity, and highest ratio of DNA protection against hydroxyl radicals, of $68.9 \%$ (15). Thus, the puffer fish sauce showed high antioxidant activity against peroxyl and hydroxyl radicals from the viewpoint of radical elimination capacity or scavenging activity and DNA protection. This is not generally characteristic of fish sauce, based on the correlation coefficient data as seen in Fig. 4. We speculate that some peptides, including oligopeptides, may contribute to the high antioxidant activity of the puffer fish sauce (unpublished data). Furthermore, puffer fish sauce and fish sauces containing soybean, wheat and koji mold tended to have higher ORAC values and lower ESR $\mathrm{IC}_{50}$ values. As previosly suggested by Ando et al, aminocarbonyl reaction products, i.e., melanoidin produced during fermentation from soybean, wheat and koji mold, contribute to the high antioxidant activities in such sauces (13).

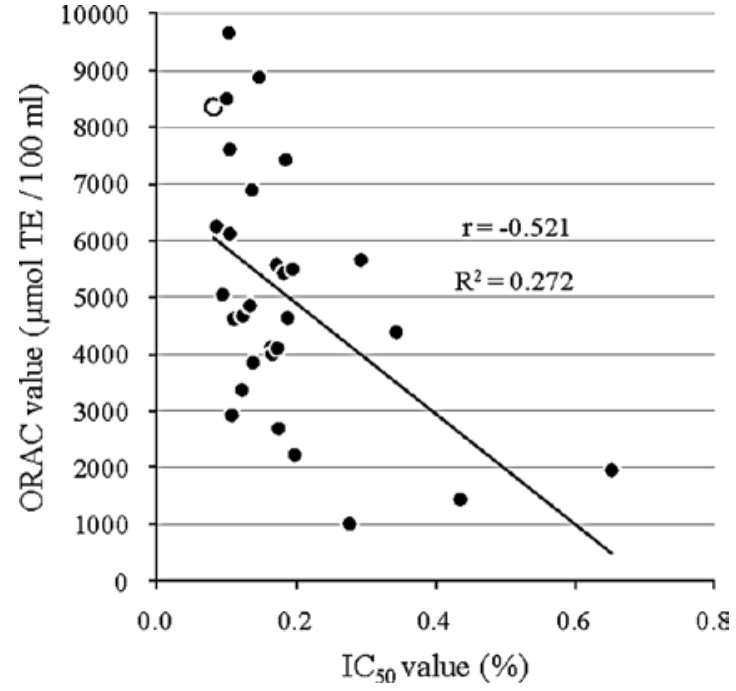

Figure 4. Relationship between $\mathrm{ORAC}$ and $\mathrm{IC}_{50}$ values of the 30 types of fish sauce. The open circle represents the puffer fish sauce.

Hernández-Ledesma et al reported on the angiotensinconverting enzyme (ACE)-inhibitory activity and ORAC value of $\beta$-lactoglobulin-derived peptides (35). It is known that the activity of ACE induces the onset of disease hypertension. This report by Hernández-Ledesma et al is notable as it extends the ORAC research field. As the data in this study represent hydrophilic-ORAC values, in the future it is essential to measure the lipophilic ORAC and the total ORAC values as well.

\section{Acknowledgements}

The authors are grateful to President Keiji Washio (National Fisheries University), Professor Tsuneo Shiba (Director of the Department of Food Science and Technology, National Fisheries University), Professor Mika Ohgata (Director of the Faculty of Children Care and Education, Osaka University of Comprehensive Children Education), Professor Satoshi Kitao (Director of Department of Human Nutrition, Osaka Shoin Women's University) and Dr Mami Ando (Graduate School of Human Science, Osaka Shoin Women's University) for their kind discussion. The authors are also grateful to President Yutaka Ohgata (Nishiki Soysauce Co., Ltd.), Ms. Yukie Kawamura (Vice President of the Yamaka Syoyu Company), Mr. Fumito Omata (Director of the Laboratory of Yamaka Syoyu Company) and President Masuzo Uoya (Kanese Foods Co., Ltd.) for providing the fish sauce samples. This study was supported in part by a research grant of Puffer Fish Project from the National Fisheries University from 2007 to 2009.

\section{References}

1. Kehrer JP: Free radicals as mediators of tissue injury and disease. Crit Rev Toxicol 23: 21-48, 1993.

2. Havsteen BH: The biochemistry and medical significance of the flavonoids. Pharmacol Ther 96: 67-202, 2002.

3. Harada K, Ando M, Kitao S, Sakamoto Y, Kobayashi M and Tamura Y: Measurement of antioxidative capacity of fish sauce using chemiluminescence method. Fish Sci 68 (Suppl 2): $1437-1440,2002$ 
4. Harada K, Okano C, Kadoguchi H, Okubo Y, Ando M, Kitao S and Tamura Y: Peroxyl radical scavenging capability of fish sauces measured by the chemiluminescence method. Int $\mathrm{J}$ Mol Med 12: 621-625, 2003.

5. Maeda T, Komoda H, Tsujimura A, Ito T, Shimada T, Kitao S, Ando M, Tamura Y and Harada K: Peroxyl and hydroxyl radical scavenging activities of raw and processed sea urchins measured by chemiluminescence and electron spin resonance methods. J Clin Biochem Nutr 43: S567-S570, 2008.

6. Nagatsuka N, Harada K, Ando M and Nagao K: Effect of soy sauce on the antioxidative capacity of the gelatin gel food 'Nikogori' measured using the chemiluminescence method. Int J Mol Med 16: 427-430, 2005.

7. Nagatsuka N, Sato K, Harada K and Nagao K: Radical scavenging activity of 'Nikogori' gelatin gel food made from head, bone, skin, tail and scales of fishes measured using the chemiluminescence method. Int J Mol Med 20: 843-847, 2007.

8. Nagatsuka N, Harada K, Ando $\mathrm{M}$ and Nagao K: Effect on the radical scavenging activity of Nikogori gelatin gel of its components and kind of added soy sauce measured by the chemiluminescence method. J Cookery Sci Jpn (in Japanese) 40: 179-183, 2007.

9. Nagatsuka N, Komatsu A, Harada K and Nagao K: Application of the Nikogori residue for food use: Sensory characteristics and radical scavenging activity of pound cakes mixed with the residue. J Cookery Sci Jpn (in Japanese) 42: 404-409, 2009.

10. Yamada J, Akahori Y, Matsuda H, Hasegawa Y, Maeda T and Harada K: Active oxygen scavenging by Katsuo-dashi dried bonito stock. J Cookery Sci Jpn (in Japanese) 43: 24-30, 2010.

11. Awatsuhara R, Harada K, Nomura T, Nikaido O and Nagao K Alteration of antioxidative activity of rutin treated with food protein. J Clin Biochem Nutr 43: S512-S515, 2008.

12. Awatsuhara R, Harada K, Maeda T, Nomura T and Nagao K: Antioxidative activity of the buckwheat polyphenol rutin in combination with ovalbumin. Mol Med Rep 3: 121-125, 2010

13. Ando M, Harada K, Kitao S, Kobayashi M and Tamura $Y$ : Relationship between peroxyl radical scavenging capability measured by the chemiluminescence method and an aminocarbonyl reaction product in soy sauce. Int J Mol Med 12: 923-928, 2003.

14. Nagatsuka N, Harada K, Ando M and Nagao K: Measurement of the radical scavenging activity of chicken jelly soup, a part of the medicated diet, 'Yakuzen', made from gelatin gel food 'Nikogori', using chemiluminescence and electron spin resonance methods. Int J Mol Med 18: 107-111, 2006.

15. Harada K, Makino Y, Yamauchi T, Fukuda N, Tamaru M, Okubo Y, Maeda T, Fukuda Y and Shiba T: Efficacy of puffer fish (Takifugu rubripes) sauce in reducing hydroxyl radical to DNA assessed using the apurinic/apyrimidinic site method. Int J Mol Med 20: 309-314, 2007.

16. Chaiyanan S, Chaiyanan S, Maugel T, Huq A, Robb FT and Colwell RR: Polyphasic taxonomy of a novel Halobacillus, Halobacillus thailandensis sp. nov. isolated from fish sauce. System Appl Microbiol 22: 360-365, 1999.

17. Sen NP, Seaman SW, Baddoo PA, Burgess C and Weber D: Formation of $\mathrm{N}$-nitroso-N-methylurea in various samples of smoked/dried fish, fish sauce, seafood, and ethnic fermented/ pickled vegetables following incubation with nitrite under acidic conditions. J Agric Food Chem 49: 2096-2103, 2001.

18. Gildberg A: Utilisation of male Arctic capelin and Atlantic cod intestines for fish sauce production - evaluation of fermentation condition. Bioresour Technol 76: 119-123, 2001.

19. Cao G, Alessio HM and Cutler RG: Oxygen-radical absorbance capacity assay for antioxidants. Free Radic Biol Med 14: 303-311, 1993.
20. Cao G, Verdon CP, Wu AH, Wang $\mathrm{H}$ and Prior RL: Automated assay of oxygen radical absorbance capacity with the COBAS FARA II. Clin Chem 41: 1738-1744, 1995.

21. Ou B, Hampsch-Woodill M and Prior RL: Development and validation of an improved oxygen radical absorbance capacity assay using fluorescein as the fluorescent probe. J Agric Food Chem 49: 4619-4626, 2001.

22. Huang D, Ou B, Hampsch-Woodill M, Flanagan JA and Deemer EK: Development and validation of oxygen radical absorbance capacity assay for lipophilic antioxidants using randomly methylated beta-cyclodextrin as the solubility enhancer. J Agric Food Chem 50: 1815-1821, 2002.

23. Huang D, Ou B Hampsch-Woodill M, Flanagan JA and Prior RL: High-throughput assay of oxygen radical absorbance capacity (ORAC) using a multichannel liquid handling system coupled with a microplate fluorescence reader in 96-well format. J Agric Food Chem 50: 4437-4444, 2005.

24. Wu X, Beecher GR, Holden JM, Haytowitz DB, Gebhardt SE and Prior RL: Lipophilic and hydrophilic antioxidant capacities of common food in the United States. J Agric Food Chem 52: 4026-4037, 2004.

25. Huang D, Ou B and Prior RL: The chemistry behind antioxidant capacity assays. J Agric Food Chem 53: 1841-1856, 2005.

26. Prior RL Wu X and Schaich K: Standardized methods for the determination of antioxidant capacity and phenolics in foods and dietary supplements. J Agric Food Chem 53: 4290-4302, 2005.

27. Kohama K, Kishi A, Ohsawa J, Sawai H and Nagasawa T: Estimation of radical scavenging activities using various methods and antioxidant activity of wild grapes (Vitis coigenetiae). J Iwate Industrial Research Institute (in Japanese) 10: 77-80, 2003

28. Wen X, Takenaka M, Murata M and Homma S: Antioxidative activity of a zinc-chelating substance in coffee. Biosci Biotechnol Biochem 68: 2313-2318, 2004.

29. Kurihara H, Fukami H, Asami S, Toyoda Y, Nakai M, Shibata H and Yao X-S: Effects of oolong tea on plasma antioxidative capacity in mice loaded with restraint stress assessed using the oxygen radical absorbance capacity (ORAC) assay. Biol Pharm Bull 27: 1093-1098, 2004.

30. Takebayashi J, Yagi Y, Ishii R, Abe S, Yamada K and Tai A: Antioxidant properties of 2-O- $\beta$-D-glucopyranosyl-L-ascorbic acid. Biosci Biotechnol Biochem 72: 1558-1563, 2008.

31. Mikami I, Yamaguchi $M$, Shinmoto $H$ and Tsushida $T$ : Development and validation of a microplate-based $\beta$-carotene bleaching assay and comparison of antioxidant activity (AOA) in several crops measured by $\beta$-carotene bleaching, DPPH and ORAC assays. Food Sci Technol Res 15: 171-178, 2009.

32. Yamada J, Akahori Y, Matsuda H, Hasegawa Y, Maeda T and Harada K: Correlation between DPPH radical scavenging activity and ORAC on dried bonito and other stocks. J Cookery Sci Jpn (in Japanese) 43: 2010 (In press).

33. Yamada J, Akahori Y, Matsuda H, Hasegawa Y, Maeda T and Harada K: Antioxidative activity of traditional Japanese seasoning dried bonito stock (Katsuo-dashi). J Ocean Univ China (Ocean Coast Sea Res) 9: 2010 (In press).

34. Oxygen radical absorbance capacity (ORAC) of selected foods2007. US Department of Agriculture, Agricultural Research Service, Beltsville Human Nutrition Research Center, Nutrition Data Laboratory, Beltsville, Maryland, pp1-34, 2007.

35. Hernández-Ledesma B, Amigo L, Recio I and Bartolomé B: ACE-inhibitory and radical-scavenging activity of peptides derived from $\beta$-lactoglobulin $\mathrm{f}(19-25)$. Interactions with ascorbic acid. J Agric Food Chem 55: 3392-3397, 2007. 